\title{
Desafios na Pesquisa em Educação Médica
}

\section{Challenges in Medical Education Research}

\author{
Hermila Tavares Vilar Guedes ${ }^{I}$ \\ Suely Grosseman \\ Nildo Alves Batista ${ }^{I}$ \\ Denise Herdy Afonso \\ Sandro Schreiber de Oliveiral \\ Douglas Vinícius Reis Pereira \\ Eduardo Arquimino Postal
}

\begin{abstract}
Assumimos a gestão da Associação Brasileira de Educação Médica (ABEM) em novembro de 2018 com o objetivo de fazer cumprir sua missão e sua visão como protagonista na melhoria da educação médica brasileira, influenciando as políticas públicas de educação e saúde, considerando o Sistema Único de Saúde e a construção de uma sociedade mais justa e igualitária. ${ }^{1}$ Nesse sentido, a Revista Brasileira da Educação Médica (RBEM) é um veículo que incentiva a construção de conhecimentos sobre educação médica e amplia sua divulgação e debate entre gestores, docentes, discentes e preceptores de instituições de ensino e serviços de saúde. O periódico vem sendo publicado há quatro décadas e tornou-se bastante reconhecido na área de ensino/educação na saúde no Brasil e em países da América Latina.

Publicações recentes divulgadas nos periódicos The American Statistician ${ }^{2}$ e Nature nos convocam a pensar sobre diversos aspectos relacionados à pesquisa científica e à educação médica. The American Statistician dedicou um suplemento inteiro, com contribuições de diversos autores na discussão sobre a mudança em alguns conceitos estatísticos, antes tidos como verdades bem estabelecidas. O editorial da publicação ressalta a preocupação com a pouca capacidade dos pesquisadores em replicar os resultados publicados, com a qualidade inapropriada da formulação de questões de pesquisa e com o excesso de testes estatísticos. ${ }^{2}$ Critica-se, portanto, a subvalorização do pensar a pesquisa e a supervalorização do "testar" seus achados. Por isso, é enfatizada a necessidade de expansão do "treinamento" estatístico, no qual o domínio da estatística abranja não apenas o cálculo, mas todo o processo científico, desde a elaboração de uma questão clara de pesquisa até sua conexão com os métodos de análise para melhor respondê-la. Quanto à análise de dados, um fato marcante é a proposta de que o valor de $p$ não seja mais dicotômico, mas sim um continuum; e que os intervalos de confiança sejam considerados como intervalos de compatibilidade, relativizando-se o alcance dos achados.
\end{abstract}

Entre alguns desafios apontados para as pesquisas futuras estão: não basear as conclusões dos estudos apenas no fato de que uma associação ou efeito foi estatisticamente significante/significativo; não acreditar que existe uma associação ou efeito apenas porque ele foi estatisticamente significante/significativo; não acreditar que não existe uma associação ou efeito apenas porque ele não foi estatisticamente significante/significativo, entre outros. ${ }^{2}$

Essas propostas destacam a relevância de acolher as incertezas na interpretação dos resultados das investigações, demandando que os pesquisadores sejam conscientes ao delinear as questões de pesquisa e o método de análise de dados; sejam abertos em suas afirmações sobre os resultados obtidos, relativizando os valores de $p$ e dos intervalos de confiança (ou de compatibilidade); e, enfim, sejam modestos sobre o papel da inferência estatística, 
apontando as limitações encontradas e incentivando a reprodução de estudos.

Esse processo dialético - neste momento em que a certeza dicotômica do valor do $p$ e a certeza dos achados com base nos intervalos de confiança, tão arraigadas entre os pesquisadores, passam a ser questionadas - nos remete a reflexões importantes. Uma delas é a visão da complexidade, que acolhe as incertezas na análise de fenômenos diversos. Outra é que, na área da saúde, apesar da atuação ser necessariamente baseada em evidências, ainda assim devemos levar em conta que as verdades podem ser temporárias, sendo críticos para considerar as limitações existentes nas investigações e abertos para novos achados. Devemos incentivar estudos que repliquem as investigações em outros locais para verificar seus resultados quando aplicados a diferentes realidades. Também é importante que os editores considerem a relevância de publicar não apenas estudos que apresentam resultados positivos; afinal, resultados negativos são fundamentais para ampliar a visão sobre um dado fenômeno. Finalmente, acreditamos que a não linearidade e complementaridade entre pesquisa quantitativa e qualitativa devem ser pressupostos para maior compreensão dos fenômenos investigados, desde que empregados adequadamente conforme a questão de pesquisa.

Um paralelo pode ser feito quando pensamos na educação médica e no ensino na saúde, bem como nos estudos realizados em seus diversos aspectos e dimensões. É preciso delinear o método mais adequado para responder às questões de pesquisa, as quais devem ser bem elaboradas, e é fundamental atualizar-se para acompanhar as mudanças que ocorrem ao longo do tempo, como a que está sendo proposta pelos estatísticos. É preciso também ser crítico, flexível e ter abertura na análise das evidências.

Nesse contexto, a pesquisa na educação médica e no ensino na saúde envolvem desafios permanentes, suscitando atenção a seu reconhecimento e à avaliação contínua de seu processo, o que inclui o currículo, a saúde do educador e do educando, as experiências e inovações pedagógicas, entre outros. Diversos são os temas relevantes para os cursos de graduação e pós-graduação na medicina e nas outras áreas da saúde

A gestão atual da ABEM considera que, para alcançarmos os melhores desfechos na pesquisa no ensino na saúde, é necessário valorizar esta área, bem como qualificar e incentivar os educadores que atuam em nossos cursos na área de saúde a pesquisar os desfechos de sua prática cotidiana e a investigar temas relacionados à educação e às políticas para a educação e a saúde. É fundamental divulgarmos as pesquisas e as experiências (exitosas ou não) desenvolvidas em todas as regiões do Brasil e além das fronteiras nacionais, certamente repletas de aprendizado.

A divulgação dessas produções contribui para o acúmulo de conhecimento e de evidências, incrementa o potencial de aprendizado dos leitores e propicia mais visibilidade à produção pedagógico-científica de docentes e preceptores de cursos de graduação e pós-graduação na área da saúde.

Afinal, formar médicos e outros profissionais de saúde comprometidos com o cuidado ampliado, conscientes de seu compromisso bioético e ético-profissional e dotados de uma visão abrangente da realidade social, torna indispensável a participação de cada docente e cada preceptor neste processo de construção. Pesquisar o ensino e a prática na saúde é assim uma estratégia essencial para transformar a realidade e aprimorar e potencializar o trabalho de quem ensina e aprende.

\section{REFERÊNCIAS}

1. Associação Brasileira de Educação Médica. ABEM: Estatuto, Regimento Geral e Regimento Eleitoral da ABEM. 2012. Disponível no site https://abem-educmed.org.br/ wp-content/uploads/2016/07/estatuto_regimento2012. pdf. Acesso 20 de fevereiro de 2019.

2. Wasserstein RL, Schirm AL, Lazar NA. Moving to a world beyond " $p<0.05$ ". The American Statistician. 2019;73(sup1):1-19.

3. Amrhein V, Greenland S, McShane B. Scientists rise up against statistical significance: retire statistical significance. Nature. 2019;567(7748):305-7.

\section{CONTRIBUIÇÃO DOS AUTORES}

Todos declaram ter participado igualmente na confecção do editorial.

\section{CONFLITOS DE INTERESSES}

Os autores declaram não haver.

\section{ENDERECCO PARA CORRESPONDÊNCIA}

Associação Brasileira de Educação Médica-ABEM, SCN - QD 02 -BL D- Torre A - Salas 1021 e 1023 - Asa Norte - Brasília-DF. CEP: 70.712-903.

Recebido em: 3/4/19

Aceito em: 4/4/19 